\title{
Evaporation of Musk and other Odorous Substances.
} By John Aitken, LL.D., F.R.S.

(Read July 10, 1905. MS. received July 17, 1905.)

In scientific literature the evaporation of musk has a considerable interest. Almost every writer on the divisibility of matter cites it as an instance of the extremely minute division of which matter is capable, our sense of smell enabling us to detect a more minute quantity of this form of matter than can be detected of any other kind of matter by any of the modern refined methods, such as the spectroscope, or chemical processes. It is possible we may shortly have to modify this statement, as extremely small quantities of some kinds of matter can be detected by their radio-activity; but, so far as I know, no reliable numerical values have been obtained in this direction.

To give an idea of the extreme minuteness of the particles of musk that are capable of affecting our sense of smell, the following figures may be given. Leslie, in his Natural Philosophy (1823), says, referring to a grain of musk that had perfumed a room for twenty years, "that at the lowest computation the musk had been subdivided into 320 quadrillions of particles." The following table, for which I am indebted to Dr Gordon Blackheath, gives a more recent estimate of the amount of musk that can be detected by its smell, and it will be noticed that it is not so small as Leslie's estimate. The table also shows the smallest amounts of some other kinds of matter that can be detected by the most refined methods.

Delicacy of the Sense of Smell compared with that of some of the most delicate Objective Tests.

\begin{tabular}{|c|c|c|c|}
\hline Substance. & $\begin{array}{l}\text { Smallest part of a } \\
\text { Gramme detected. }\end{array}$ & Re-agent. & Authority. \\
\hline $\begin{array}{l}\text { Musk } \\
\text { Iodoform } \\
\text { Sodium } \\
\text { Lithium } \\
\text { Nitrite }\end{array}$ & $\begin{array}{l}0 \cdot 000,000,000,000,000,01 \\
0 \cdot 000,000,000,000,01 \\
0 \cdot 000,000,000,03 \\
0 \cdot 000,000,001 \\
0 \cdot 000,000,001\end{array}$ & $\begin{array}{c}\text { Sense of Smell } \\
\text { Spectroscope } \\
\text { Ilosvay's re-agent }\end{array}$ & $\begin{array}{l}\text { Berthelot } \\
\text { ", } \\
\text { Bunsen \& Kirchoff } \\
\text { Bunsen } \\
\text { Warington }\end{array}$ \\
\hline
\end{tabular}


As the extremely small amount of musk that can be detected is likely long to retain its classical interest, and as there is a point connected with the subject on which there still seems to be some dispute, I have thought it worth while to see if the doubt could not be cleared up by some experimental methods. There seems to be a difference of opinion as to the state in which the musk exists in the air after it leaves its visible form. While some consider that it passes off as a gas or vapour, others think it goes off in solid particles. It is somewhat difficult to understand how this idea that musk passes into the air as a solid could ever come to be so strongly held, as everyone has seen snow and ice evaporating during frosty weather, and have never supposed the particles leaving the ice to be different from those leaving water.

There seem to be a number of ways in which we might test whether musk exists in the air in the form of solid particles, or as a gas. First, we might try the cloudy condensation test. If the musk is in solid particles, these particles will become nuclei of cloudy condensation in supersaturated air, and thus make their presence visible. Second, we might pass the musk-laden air through tightly-packed cotton-wool. If the musk passes through the wool, we may conclude it does so in the form of a gas, as cotton-wool keeps back all particles floating in the air. Third, we might try diffusion. If the musk is gaseous, it will diffuse through the air and not require air-currents to carry it, which would be necessary for solid particles. Diffusion through porous vessels, tightly-packed cotton-wool, etc., might also be tried, as we would hardly expect solid particles to diffuse through these. Fourthly, we might try gravitation. If the musk is in solid particles, it will settle at the bottom of the enclosure, as do the finest dust-particles in air.

Before going further, it may be as well to refer to a point which requires attention. It might be asked, May not the subdivision of solids go on so far that they may be reduced to the dimensions of molecules? And if so, How would they differ from gaseous molecules, and how would they conduct themselves when suspended in a gas? Would they take up movements similar to those of the surrounding gaseous molecules? If so, they might diffuse through the gas, and both diffusion and gravitation tests 
would have no value. There are, however, some reasons for supposing that solids are never reduced to such minute dimensions. The simplest method of showing this is by a study of the phenomena of cloudy condensation in dusty air. If we take the usual apparatus for showing cloudy condensation, a few experiments will show that the solid particles seem to have a lower limit to their size, and that they are never so small as to be capable of diffusing or not being separated but by the action of gravitation. The apparatus required for illustrating these points is shown in the figure. $\mathrm{F}$ is a glass flask provided with an indiarubber stopper, the stopper having two apertures in it, in which

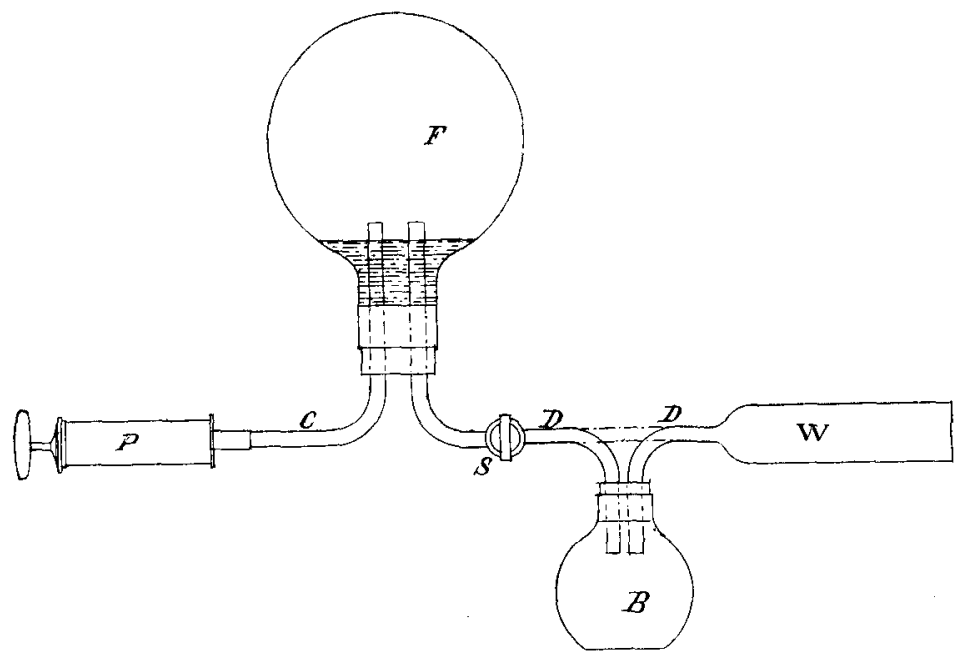

are fitted two tubes. One of the tubes, $\mathrm{C}$, is connected with an air-pump $\mathrm{P}$, and the other, $\mathrm{DD}$, shown in dotted lines, with a cotton-wool filter $\mathrm{W}$; a stop-cock, $\mathrm{S}$, being introduced in the pipe DD between the flask and the filter, as shown. A little water is put in the flask $F$ to moisten the air. Suppose, now, there is ordinary unfiltered air in the flask F. If we close the stop-cock $\mathrm{S}$, and then make the smallest degree of expansion by pulling out the pump-handle a very short length, it will be noticed that clondy condensation at once takes place, the very smallest expansion being sufficient to cause the dust nuclei to become centres of condensation. That is to say, there are particles in the air 
sufficiently large to allow of condensation taking place on them with a very slight degree of supersaturation. Now, it is well known that the vapour pressure at a convex surface is higher than at a flat surface, and that the quicker the curvature the higher is the vapour pressure. From this we see that the smaller the dust-particle the higher the supersaturation must be before it can become a nucleus of condensation; so we would expect, if the solid particles were of all sizes down to molecular, that while the larger particles might become centres of condensation in very slightly supersaturated air, the smaller ones would require a higher degree of supersaturation, and higher in proportion to their smallness. There is, however, no evidence of this, the slightest degree of supersaturation being sufficient to cause condensation on even the smallest. A simple way of showing this is to take part of the cotton-wool out of the filter $\mathrm{W}$ shown in the figure, and only leave enough of it to keep back all but a few particies. By this process we get not only a few, but these few in all probability the smallest in the entering air, and yet they require but the very slightest expansion to make them visible; and if we clear the air of them by making successive very slight expansions so as to carry them down as the nuclei of rain-drops, when all drops cease to make their appearance with these very slight expansions, we shall find that higher expansions produce no further condensation though accompanied by much higher supersaturations. The supersaturation may be made to go on increasing without any sign of condensation making its appearance till at a very high degree of supersaturation; as C. T. R. Wilson has shown, condensation takes place on the ions in the air. As all the dust-particles become centres of condensation with an extremely small amount of supersaturation, and when got rid of no condensation takes place on dust-particles with higher degrees of supersaturation, we are entitled to conclude that the particles are not of all sizes down to the molecular.

There is another experiment which supports these conclusions. If we leave the apparatus above described for a considerable time-it may be for days-after filling the flask with ordinary dusty air, it will be found that the sifting process, due to gravitation, will remove all the larger particles first, till in 
the end the finer ones are also removed; but if we test it just before the last of them fall, we shall find that the slightest expansion is sufficient to make them centres of condensation and that higher expansions and supersaturations produce no further cloudy condensation-which we would be entitled to expect under the higher strain if extremely minute particles were present. We may therefore conclude that the finest subdivided solids are still acted on by gravitation, and seem to have a definite lower limit of subdivision; unless it can be shown that extremely minute particles do not form nuclei of condensation, a conclusion for which there seems to be no warrant.

Of the different methods above described for distinguishing between solid and gaseous particles, the cloudy condensation test seems to be the best; accordingly, the odour of musk was first tested by it. The apparatus above described, and shown in the figure, was used for the purpose, a little musk being introduced into the flask $\mathrm{F}$. It is evident that if the musk gave off solid particles, it would now be impossible to get the air in the flask in such a condition that no cloudy condensation would take place when the air was expanded, because the musk would keep up a continued supply of nuclei of condensation. However, on putting the musk to the test it was found that the condensation, due to the dust-particles, which were admitted along with musk, decreased, and finally entirely ceased, just as when no musk was present; thus showing that the musk did not give off solid particles.

It was thought desirable to vary this experiment, as it was possible that the vapour-laden air in the test-flask might interfere with the result. The musk was therefore removed from the test-flask F, and put into a separate bottle, B, by itself. This bottle was provided with an air-tight stopper through which passed inlet and outlet tubes, and introduced into the apparatus between the filter and the test-flask in the manner shown in the figure. By this arrangement the musk evaporated in filtered air, of the ordinary dryness, before entering the test-flask. Tests made in this way also gave no nuclei from the musk, even when the apparatus had been left some time for a quantity of musk to evaporate.

From these experiments we may conclude that musk does not give off solid particles, but evaporaten as a gas or vapour like 
other substances-that it is gaseous particles from the musk that act on our sense of smell.

In confirmation of these results some other experiments were made. It was thought that if musk passes into the air as a gas or vapour that it would be able to pass through a quantity of cotton-wool sufficient to stop all dust-particles. To test this, part of the apparatus shown in the figure was used. The air was first passed over the musk, then through the cotton-wool filter, with the result that the perfume came freely through the cotton-wool. It did not come just at first; but after pumping a short time the scent became quite distinct, apparently as strong as when not passed through the cotton-wool. Some of the gas which first entered the filter was trapped and held by the wool, but the wool soon became sufficiently saturated to allow the musk vapour to pass. The trapped vapour remained in the wool and could easily be detected afterwards.

Having the apparatus arranged for testing the musk, it was thought advisable to test some other odorous solid substances; camphor and naphthalene were accordingly experimented with. They both acted like musk and gave no nuclei of condensation, and the gas or vapour from both passed easily through cottonwool; so we may conclude that they, like musk, evaporate in gaseous form.

It is intended to test a number of other solid odorous bodies to see if any of them give any support to the idea that they give off their perfume in solid particles.

Note added 27th July.- Since the above paper was read on 10th July, a number of other odorous substances have been tested. The cloudy condensation method of testing was used in all cases, as it seems to be the most satisfactory, and definite results were obtained by it; whereas filtering through cotton-wool and diffusion tests are at times uncertain owing to the sensitive surface-the nostrils of the observer-not always giving a definite answer, especially when fatigued; and there is the further risk of subjective sensations interfering with the correctness of the results. Diffusion tests made with ordinary porous cells are somewhat unsatisfactory, owing to some of the vapour being condensed in the 
pores of the cell. Camphor, for instance, comes freely through the walls of the cell, but at first only in small quantity; but the smell outside becomes stronger with time, and if the camphor be removed from the interior of the cell, the outside of the cell continues to give off the smell of camphor for days. Some of the camphor is evidently condensed in the pores and is slowly given off, just as water vapour is condensed and slowly given off under similar conditions, Both the filter and diffusion tests were, however, used in some cases as checks on the condensation method.

The following table shows the substances tested. Many of them are entered under their ordinary commercial names. All of them, with the exception of the metals, flowers, and herbs, were tested in the apparatus shown in the figure. For testing the metals, etc., a larger flask than $B$ was used. The metals were in the form of wires-a quantity being coiled up and placed in the bottle. The result of the tests was that not one of the twenty-three substances gave off their perfume in solid particles, nothing but gases or vapours escaping from them.

\section{List of Substances Tested.}

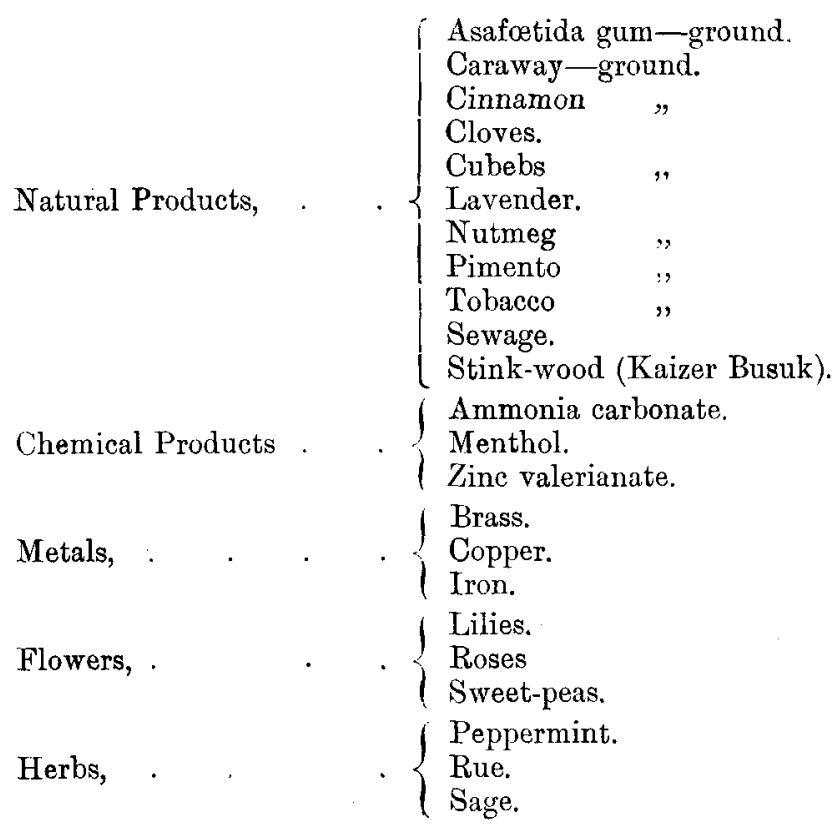


All the substances entered under natural and chemical products were samples of ordinary articles of commerce, and I am indebted to Sir John Murray for the piece of Kaizer Busuk from Christmas Island which was used in the tests. This wood has a very strong and extremely offensive smell, strong enough and heavy enough to suggest solid particles; yet it, like the others, only gives off gas or vapour. It may be interesting to sanitarians to know that sewage does not communicate to the air any solid particles, that the offensive emanation is a gas. As there seemed to be some doubt on this subject it was thought advisable to test itthough one would hardly expect solid or liquid particles to leave a wet surface. Further, it is known that the air in sewers is remarkably free from germs of all kinds, as they do not leave the sewage; and if they are in the air they soon settle. If sewage gave off solid or liquid particles these also would soon settle on the surface of the sewage. These remarks apply only to sewers in which the sewage flows easily and without break in its surface film. If it is stirred up or flows rapidly, especially if over falls, then both germs and particles of the sewage get mixed up with the air, as the bursting of each bubble scatters a number of minute particles of sewage.

Our nostrils seem to confirm the conclusion that the perfume given off by substances is not in the same form, and probably often not of the same composition, as the matter from which it is emitted. Take the effect of tobacco-snutf, for instance; the perfume from it is perfectly distinct from the sensation produced when the dust of tobacco comes in contact with the nasal passages. The perfume is a soft and velvety sensation; while the effect of the solid is sharp and biting, more allied to pain than pleasure. It may be said that this painful sensation is only the natural effect of overstimulation of the nerves, just as the feeling of a fire is pleasant at a distance, while contact with the live coals is painful. The two sense perceptions are, however, so dissimilar it would be unsafe to draw too close a comparison. If they were similar, then an excess of all perfumes ought to be painful if the dust effect of the snuff were only an excess of perfume. But this is not the case. Musk, when snuffed, has hardly any effect, only the musky odour felt when no musk dust touched the nostrils. Other substances, such 
as pimento, menthol, and many others, when snuffed also produce a sensation in the nostrils quite different from that of their perfume. Curiously enough, they all produce a similar sensation, and only vary in degree; and all of them give a sensation similar to that of tobacco-snuff, which is more an irritation than a smell. Of course, when these substances are applied to the nostrils in the form of powders the sensation is compounded of the contact effect of the dust and of the perfume; the latter is probably perceived by some part of the surface not affected by the dust. It is probable that none of the dust ever comes in contact with the more sensitive part of the olfactory surfaces, which are out of reach of the direct air-currents. When we consider that all these odorous substances in the form of fine powders give rise to almost the same sensation, though in varying degrees, the probability is they are all perceived by the branch of the fifth nerve, which serves the inside of the nostril over which the main air-currents flow, and have no effect on the olfactory nerve, on which only gases or vapours appear to act. 